\title{
A DisaggregationEmulation Approach for Optimization of Large Urban Drainage Systems
}

DOI:

10.1029/2020WR029098

\section{Document Version}

Final published version

Link to publication record in Manchester Research Explorer

\section{Citation for published version (APA):}

Seyedashraf, O., Bottacin Busolin, A., \& Harou, J. J. (2021). A DisaggregationEmulation Approach for Optimization of Large Urban Drainage Systems. Water Resources Research . https://doi.org/10.1029/2020WR029098

\section{Published in:}

Water Resources Research

\section{Citing this paper}

Please note that where the full-text provided on Manchester Research Explorer is the Author Accepted Manuscript or Proof version this may differ from the final Published version. If citing, it is advised that you check and use the publisher's definitive version.

\section{General rights}

Copyright and moral rights for the publications made accessible in the Research Explorer are retained by the authors and/or other copyright owners and it is a condition of accessing publications that users recognise and abide by the legal requirements associated with these rights.

\section{Takedown policy}

If you believe that this document breaches copyright please refer to the University of Manchester's Takedown Procedures [http://man.ac.uk/04Y6Bo] or contact uml.scholarlycommunications@manchester.ac.uk providing relevant details, so we can investigate your claim.

\section{OPEN ACCESS}




\section{Water Resources Research}

\author{
RESEARCH ARTICLE \\ 10.1029/2020WR029098 \\ Key Points: \\ - A new surrogate-based optimization \\ approach is presented for \\ disaggregation and optimization of \\ large urban drainage networks \\ - Artificial neural networks are used \\ to represent the hydraulic head at \\ the interface between two parts of a \\ disaggregated drainage network \\ - The proposed method significantly \\ reduces the computational cost \\ of optimization when the area of \\ interest is a subregion of a larger \\ area
}

Supporting Information:

Supporting Information may be found in the online version of this article.

\section{Correspondence to:}

A. Bottacin-Busolin,

andrea.bottacinbusolin@manchester. ac.uk

\section{Citation:}

Seyedashraf, O., Bottacin-Busolin, A., \& Harou, J. J. (2021). A disaggregation-emulation approach for optimization of large urban drainage systems. Water Resources Research, 57, e2020WR029098. https://doi. org/10.1029/2020WR029098

Received 25 OCT 2020 Accepted 22 JUL 2021
(C) 2021. American Geophysical Union. All Rights Reserved.

\section{A Disaggregation-Emulation Approach for Optimization of Large Urban Drainage Systems}

\author{
Omid Seyedashraf $^{1}$ (D), Andrea Bottacin-Busolin ${ }^{1}\left[\right.$, and Julien J. Harou ${ }^{1,2}$ (D) \\ ${ }^{1}$ Department of Mechanical, Aerospace and Civil Engineering, The University of Manchester, Manchester, UK, \\ ${ }^{2}$ Department of Civil, Environmental and Geomatic Engineering, University College London, London, UK
}

\begin{abstract}
Multi-objective optimization can help identify efficient and appealing designs of urban drainage systems. However, their application to large-scale problems is hindered by the computational cost of urban drainage simulation. We propose a novel disaggregation approach that allows simulating a portion of a drainage network while the remaining part is represented by a surrogate model that maps changes in the region of interest to hydraulic head time-series at synthetic nodes shared with the remaining part of the network. The proposed approach is demonstrated with an application to the many-objective optimization of sustainable urban drainage systems in two urban areas. The design problem's decision variables include the types of sustainable drainage systems, their combination within a subcatchment, their surface areas and spatial distribution, whereas the objectives include the minimization of capital cost, flood volume, flood duration, and total suspended solids or average peak runoff. The results show that the proposed disaggregation-emulation approach can provide an accurate representation of the system dynamics while significantly reducing the computational time compared to a model that simulates the whole network dynamics. Two alternative surrogate models are considered based on multilayer perceptron (MLP) and generalized regression neural networks (GRNN). MLP is found to be more accurate compared to GRNN at the cost of a larger computational time for the training process.
\end{abstract}

\section{Introduction}

Rapid expansion of cities has increased the severity of flooding events by converting large pervious areas into impervious roads, rooftops and parking lots, which inhibit the natural storage and infiltration of runoff water. Sustainable urban drainage systems (SuDS) can help reduce the risk of flooding, while providing a number of additional co-benefits, such as improved water quality, aesthetics, and recreational value. Flood mitigation plans require consideration of several, often conflicting objectives, which complicates the design process. Several previous studies have tackled this multi-criteria design problem using meta-heuristic optimization algorithms (Duan et al., 2016; Vojinovic et al., 2014; Yazdi et al., 2018) coupled with simulation tools such as the Storm Water Management Model (SWMM; Duan et al., 2016; K. Eckart et al., 2018; Gironás et al., 2010; Lin et al., 2020; Macro et al., 2019; Vojinovic et al., 2014; Xu et al., 2017; Yazdi et al., 2018), the Soil and Water Assessment Tool (SWAT; Geng et al., 2019; Maringanti et al., 2009), or MIKE FLOOD (W. Zhang et al., 2019). However, optimization methods usually entail tens (or hundreds) of thousands of numerical simulations, which are computationally demanding when applied to large drainage networks. This is the main reason why optimized design is not commonly used in industry. A possible solution to this problem is to replace the simulation of the system dynamics with computationally cheaper surrogate models. These include the Gaussian process emulator (Mahmoodian, Torres-Matallana, et al., 2018; Owen \& Liuzzo, 2019), artificial neural networks (ANNs; Kim et al., 2019; Latifi et al., 2019; Sayers et al., 2014, 2019; Seyedashraf, Mehrabi, et al., 2018; Yazdi \& Salehi Neyshabouri, 2014), or conceptual models with simplified structures that mimic specific outputs of the real system (Mahmoodian, Carbajal, et al., 2018; Mahmoodian, Torres-Matallana, et al., 2018).

Artificial neural networks (ANNs) have been widely used to describe the relationship between rainfall and flooding (Abou Rjeily et al., 2017, 2018; Chang et al., 2014; Chiang et al., 2010; Kim et al., 2019; She \& You, 2019). Chiang et al. (2010) used recurrent neural networks to track water level patterns in a sewerage system using the historical rainfall records in an urban catchment. Later, Abou Rjeily et al. (2017) used a nonlinear autoregressive model with exogenous inputs (NARX) to establish similar relationships between rainfall events and flood volume patterns in a drainage system in Lille, France. She and You (2019) coupled 
NARX with radial basis function (RBF) network to predict outflow rates of a drainage system using an identical approach. In these studies, the emulation models were used to predict water depth changes based on different hyetographs, but did not consider the possibility of changes to the network properties, making them inapplicable to design optimization problems. In this regard, surrogate models were used to predict system design objectives, for example, flood volume (W. Zhang et al., 2019) and total suspended solids (TSS; Latifi et al., 2019; Raei et al., 2019), for specific network designs. For example, W. Zhang et al. (2019) used ANN to emulate the outputs of MIKE FLOOD in a two-objective urban drainage infrastructure design problem. ANN was used to predict the overall flood volume in the urban catchment. Later, Raei et al. (2019) and Latifi et al. (2019) used multilayer perceptron (MLP) neural networks as objective functions in a multi-objective optimization problem. They used multi-objective evolutionary optimization to minimize biochemical oxygen demand and TSS in an urban catchment in Tehran, Iran.

The main motivations of existing surrogate-based optimization approaches are (a) delivering quick predictions with lower computational burden, (b) ability to deal with complex nonlinear problems, and (c) accommodating several input variables and outputs in a single model run (Seyedashraf, Rezaei, et al., 2018). However, there are also inherent limitations associated with these approaches. For instance, using emulation models to evaluate objective functions in optimization approaches can bias the search process and lead to suboptimal decisions. As model errors accumulate over subsequent iterations, the optimization becomes increasingly unreliable. This is further exacerbated in multi-objective optimization problems where several objectives need to be evaluated, and where several different scenarios may need to be considered to evaluate system performance. Furthermore, the complexity of the emulation model can increase dramatically with the number of input variables in large drainage networks. There is also need for methods that allow the application of optimization algorithms to sub-regions of a larger urban area without having to solve the network dynamics for the whole system. This is often the case because constraints in capital and human resources require infrastructure investment decisions to be taken sequentially for different subcatchments within an urban area.

To overcome these limitations this paper proposes a novel method for large-scale urban drainage infrastructure optimization which involves disaggregation and optimization of only one part of the system. Surrogate modeling is used to emulate the hydraulic head at synthetic nodes at the cut-points between the region of interest and the remaining part of the system, and thereby provide interface boundary conditions for the hydraulic head and the inflow in response to changes in drainage assets within the region of interest. This approach is demonstrated with an application to many-objective optimization of sustainable drainage infrastructure in two relatively large urban areas. We evaluate the performance of Multilayer Perceptron (MLP) and Generalized Regression Neural Network (GRNN) as two alternative surrogate models and show that MLP provides best performance in terms of computational time and accuracy. The proposed approach significantly decreases the computational cost of large-scale optimization problems when the design area of interest is a subregion of a larger area.

\section{Methodology}

The proposed disaggregation methodology allows a region of interest within a larger urban catchment to be simulated without having to simulate the dynamics of the full drainage network. First, new synthetic computational nodes are generated along the conduits at the cut-points between the region of interest and the remaining part of the network. These nodes are represented as junctions with a sufficiently high maximum surcharge depth to allow water to pond atop the ground surface in case of pressurized flow in the conduits, and to flow back into the drainage system as the pressure decreases. At each synthetic node, a surrogate model is used to represent the boundary conditions for the region of interest. When applied to the optimization of drainage infrastructure within the region of interest, the surrogate model must be able to predict changes in the boundary conditions in response to changes to the infrastructure in the same region. To this end, the surrogate model is trained to represent the time-series of hydraulic head and inflow rates at the cut-points for several alternative infrastructure designs. Training datasets can be constructed by randomly generating several instances of the decision variables and evaluating the system dynamics using an urban drainage model representing the whole network. In this work, drainage simulations are conducted using SWMM, and an MLP neural network and a GRNN are evaluated as two alternative surrogate models for 


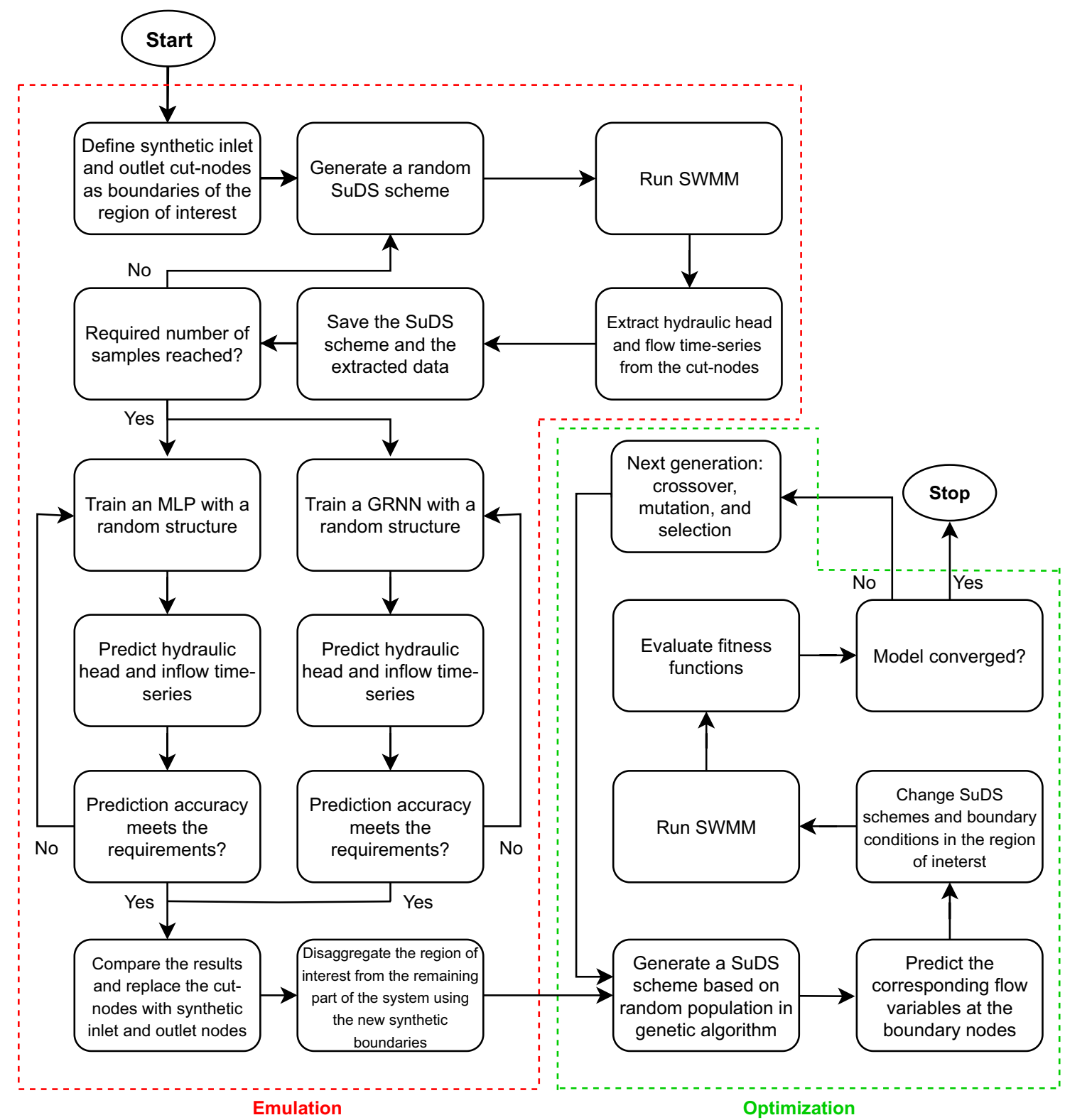

Figure 1. Flowchart of the proposed surrogate-based optimization approach applied to the design of sustainable drainage systems (SuDS).

the boundary condition at the synthetic junctions. Accordingly, the surrogate model provides flow and/or hydraulic head at the synthetic junctions for each drainage infrastructure design evaluated by the optimization algorithm. Drainage is then simulated for the region of interest only, with the emulated boundary conditions representing the interactions between the region of interest and the remaining part of the drainage network. A flow chart of the proposed emulation-based optimization approach is presented in Figure 1. The proposed methodology is applied to two optimization problems where sustainable drainage systems are used to expand the capacity of two urban drainage networks in different subregions.

\subsection{Numerical Drainage Model}

The SWMM model was used to simulate the dynamics of the drainage system. SWMM is a dynamic rainfall-runoff, flow routing, and water quality modeling software, which has been widely used for urban drainage analysis and design (Gironás et al., 2010). Three flow routing models can be used in SWMM, including 
steady flow, kinematic wave, and dynamic wave. In this study, the latter model was used, as it can replicate pressurized and backwater flow effects by solving the one-dimensional Saint-Venant equations (James et al., 2010; Meza \& Oliva, 2003; Triki, 2017):

$$
\begin{gathered}
\frac{\partial A}{\partial t}+\frac{\partial Q}{\partial x}=0 \\
\frac{\partial Q}{\partial t}+\frac{\partial\left(Q^{2} / A\right)}{\partial x}+g A \frac{\partial h}{\partial x}+g A\left(S_{f}+h_{L}\right)=0
\end{gathered}
$$

where $t$ is time, $x$ is distance, $g$ is gravitational acceleration, $h$ is the hydraulic head, $A$ is the flow cross-sectional area (function of $h$ ), $Q$ is flow discharge $S_{f}$ is the friction slope, and $h_{L}$ represents local energy loss per unit length of the conduit.

Storm Water Management Model (SWMM) is capable of simulating stormwater pollution build-up, washoff, and transport (Gironás et al., 2010) using different empirical relationships. In its latest versions, SWMM allows modeling of different types of SuDS (James et al., 2010; Meza \& Oliva, 2003; Rossman \& Huber, 2016), including bio-retention cells, rain gardens, green roofs, infiltration trenches, permeable pavements, rain barrels, rooftop disconnections, and vegetative swales (Rossman \& Huber, 2016).

\subsection{Surrogate Model for Interface Boundary Conditions}

Two ANN-based machine-learning methods are used as surrogate models to represent the hydraulic head and total inflow at the synthetic junctions at the interface between the region of interest and remaining part of the system. ANNs are input-output mathematical models based on the operation of biological nervous systems that consist of interconnected neurons (Du \& Swamy, 2006; Tadeusiewicz, 1995). ANNs have three main advantages: (a) they can learn non-linear relationships between system components, (b) they have inherently distributed nature that allows better implementation across distributed systems, and (c) they use specific internal optimization methods to find efficient architecture components. Neurons are the basic processing elements of ANNs with synapses considered as weights. Training inputs are encoded in the first layer and passed through the hidden layers via weighted links while the data redistribute through the neurons. In each neuron, the weighted data are summed up, together with a scalar parameter $b$ known as "bias" to be used by a predefined transfer function. The information obtained from the transfer function is the input data to the nodes in the subsequent layers. The outputs of the first neuron would be as follows:

$$
O=f\left(\sum_{i=1}^{N_{e}}\left(u_{i} w_{i}\right)+b\right)
$$

where $u_{i}$ is the input vector, $N_{e}$ denotes the number of elements in the input vector, $w_{i}$ is the $i$ th weight of the neuron, $b$ is the bias, and $f$ is the transfer function.

Various transfer functions may be used, including sigmoid transfer function and a linear transfer function, which are commonly used in hidden and output layers, respectively (Seyedashraf, Rezaei, et al., 2018). In this study, two ANN models, namely MLP and GRNN, were evaluated in terms of accuracy and efficiency.

\subsubsection{Multilayer Perceptron Network}

Multilayer perceptron (MLP) is a feedforward ANN architecture (Hornik et al., 1989), which is by far the most popular ANN used in a variety of water engineering applications (Broad et al., 2005; Maier et al., 2010; Seyedashraf, Rezaei, et al., 2018). In feedforward ANN, each node of a layer receives information from nodes of a preceding layer and processes it before feeding it to the neurons of a subsequent layer. There is a minimum of three layers in MLP networks, including an input layer, at least one hidden layer, and an output layer. Each node of a layer connects to every node of a subsequent layer with certain weighting factors.

The input-output relationship is the same for all the nodes of the network and is expressed by Equation 3, where the transfer function $f$ is most commonly a sigmoid function in the form: 


$$
f(z)=\frac{1}{1+\exp (z)}
$$

The complexity and accuracy of an MLP network changes with the number of hidden layers. A lower number is preferable, as the complexity of the training process increases with the number of hidden layers.

\subsubsection{Generalized Regression Neural Network (GRNN)}

Generalized regression neural network (GRNN; Specht, 1991) is a one-pass learning algorithm with a feed-forward architecture. This network is especially suitable for prediction purposes in multidimensional problems with sparse data (Specht, 1991). There are four layers in this network: (a) an input layer that includes the input vectors and feeds encoded input information to the next layer; (b) a pattern layer that calculates the Euclidean distance and activation function; (c) a summation layer that contains two types of neurons, including numerator and denominator, which calculate the arithmetical sum of the pattern layer with and without weights, respectively; and (d) an output layer, which contains one neuron and calculates model outputs according to the information received from the summation layer.

GRNN maps the input space to the output space as follows (Specht, 1991; X. Zhang et al., 2019):

$$
\begin{gathered}
y(x)=\frac{\sum_{i=1}^{N_{s}} y_{i} \exp \left(-D_{i}^{2} / 2 \sigma^{2}\right)}{\sum_{i=1}^{N_{s}} \exp \left(-D_{i}^{2} / 2 \sigma^{2}\right)} \\
D_{i}=\sqrt{\left(x-x_{i}\right)^{T}\left(x-x_{i}\right)}
\end{gathered}
$$

where $y_{i}$ is the $i$ th output corresponding to input $x_{i}, N_{s}$ is the number of samples in the input vector, and $\sigma$ is the smoothing factor, which is used to adjust neurons' sensitivity to changes in the input vector.

A larger smoothing factor results in smooth function approximations and improves the generalization of the predictions while reducing the accuracy of the predictions.

\subsection{Optimization}

A multi-objective optimization problem consists of a set of objective functions to be minimized (or maximized):

$$
\underset{l \in \phi}{\operatorname{Minimize}}: \boldsymbol{F}(\boldsymbol{l})=\left(F_{1}, F_{2}, \ldots, F_{N_{o}}\right)
$$

where $\boldsymbol{F}$ is a vector of objective functions representing the performance of the system, $\boldsymbol{l}$ is a vector of decision variables, $N_{o}$ is the number of objectives, and $\phi$ is the decision space. Typically, the solutions to Equation 7 must satisfy a set of constraints, which can generally be written in the form:

$$
\begin{gathered}
C_{\mathrm{eq}, j}(\boldsymbol{l})=0 \quad j=1, \ldots, N_{q} \\
C_{\mathrm{in}, k}(\boldsymbol{l}) \leq 0 \quad k=1, \ldots, N_{r}
\end{gathered}
$$

where $C_{\mathrm{eq}, j}(\boldsymbol{l})$ and $C_{\mathrm{in}, k}(\boldsymbol{l})$ are functions of the decision variables, and $N_{q}$ and $N_{r}$ are the number of equality and inequality constraints, respectively.

Multi-objective optimization models can be used to find non-dominated multi-dimensionally efficient (Pareto optimal) solutions. In a multi-objective optimization problem, the decision space is mapped into the objective space, and extreme points are located using a search algorithm. Initially proposed by Deb et al. (2002), non-dominated sorting genetic algorithm II (NSGA-II) is a popular and efficient multi-objective optimization algorithm widely used in stormwater management problems (Hooshyaripor \& Yazdi, 2017; Liu et al., 2019; Manocha \& Babovic, 2018; Ngamalieu-Nengoue et al., 2019; Penn et al., 2013; $\mathrm{Xu}$ et al., 2017). In NSGA-II, optimization objectives are explored based on an elitist genetic algorithm, 
in which individuals with better ranks are selected in each generation until non-dominated solutions are found. In this study, the controlled version of NSGA-II (CNSGA-II), (Deb \& Goel, 2001) is used, which favors non-elitist individuals that can widen the distribution of the population space. Comparing to the original NSGA-II, CNSGA-II has superior convergence properties and can find solutions with improved distributions by maintaining diversity in Pareto-fronts (Deb \& Goel, 2001).

In case study 2, the Borg Multi-Objective Evolutionary Algorithm (MOEA) was used. Borg MOEA is an advanced optimization algorithm based on genetic principles that relies on various search algorithms to provide improved reliability (Hadka \& Reed, 2013). Borg MOEA has been shown to perform well in multi- and many-objective optimization problems of urban drainage and sewer system design (K. Eckart et al., 2018; Q. Zhang et al., 2021).

\section{Application of the Proposed Approach}

Two case studies were considered to demonstrate the applicability of the proposed framework. In the first case study, the region of interest is located in the middle of an urban catchment and has several cut-nodes connecting the region of interest to the rest of the network. In the second case study, instead, the region of interest is located in the upstream part of an urban drainage system. This case study highlights the impact of alterative SuDS schemes on the hydraulic head time-series at the cut-nodes.

\subsection{Case Studies}

Case study 1 is an $8.0 \times 10^{5} \mathrm{~m}^{2}$ urban catchment, comprising 64 subcatchments, 566 manholes, and 511 conduits. This case study is taken from the work of Riaño-Briceño et al. (2016), which presents an opensource toolbox for real-time control in drainage systems. The case study is a modified version of a real urban drainage system in Bogotá, Colombia. As explained before, the urban drainage system was artificially disaggregated into a region of interest and the remaining part of the system. In this case, there are three conduits linking the two sub-systems, therefore three synthetic manholes are created at the cut-points between the two. The region of interest includes 5 subcatchments, 29 junctions, and 23 conduits. Figure 2 shows a planview of the drainage system with indication of the conduits, manholes and subcatchments, and with the region of interest highlighted in yellow color. The hyetograph of the design rainfall event is shown in Figure S1.

Case study 2 is a $6.3 \times 10^{5} \mathrm{~m}^{2}$ urban catchment area located in Windsor, Canada (K. Eckart et al., 2018; K. B. C. Eckart, 2015), comprising 227 subcatchments, 117 junction nodes, and 122 conduit links. Only one conduit links the region of interest to the remaining part of the network (Figure 3). The boundary of the region of interest encloses all the nodes that receive an inflow from such region. The synthetic outfalls are located at the cut-points where the boundary of the region of interest intersects the drainage pipes. The hyetograph of the design rainfall event for case study 2 is provided in Figure S2.

To capture the extent of the potential variation of the hydraulic head in the training of the emulation model, we sampled the surface area of the SuDS components from four intervals of the impervious surface area in each subcatchment, namely $0 \%-7.5 \%, 7.5 \%-15 \%$, and $15 \%-20 \%$, as well as the overall interval $0 \%-20 \%$. The optimization model searches for Pareto-optimal types, combinations, spatial distributions, and surface areas of SuDS in the region of interest based on four design objectives in each case study, including minimization of capital cost, flood volume, flood duration in both case studies, and TSS and average peak runoff rate in case study 1 and 2, respectively. Six different types of sustainable drainage assets are considered. These include bio-retention cells, rain gardens, green roofs, infiltration trenches, permeable pavements, and rain barrels. The exponential function and event mean concentration methods were used for estimating TSS build-up and wash-off load (Rossman \& Huber, 2016).

\subsection{Optimization of SuDS Design}

The proposed disaggregation approach was demonstrated with an application to many-objective SuDS optimization problems, where the term "many-objective" denotes a problem with four or more objectives (Fleming et al., 2005). Four design parameters, including type of drainage assets and combination within 


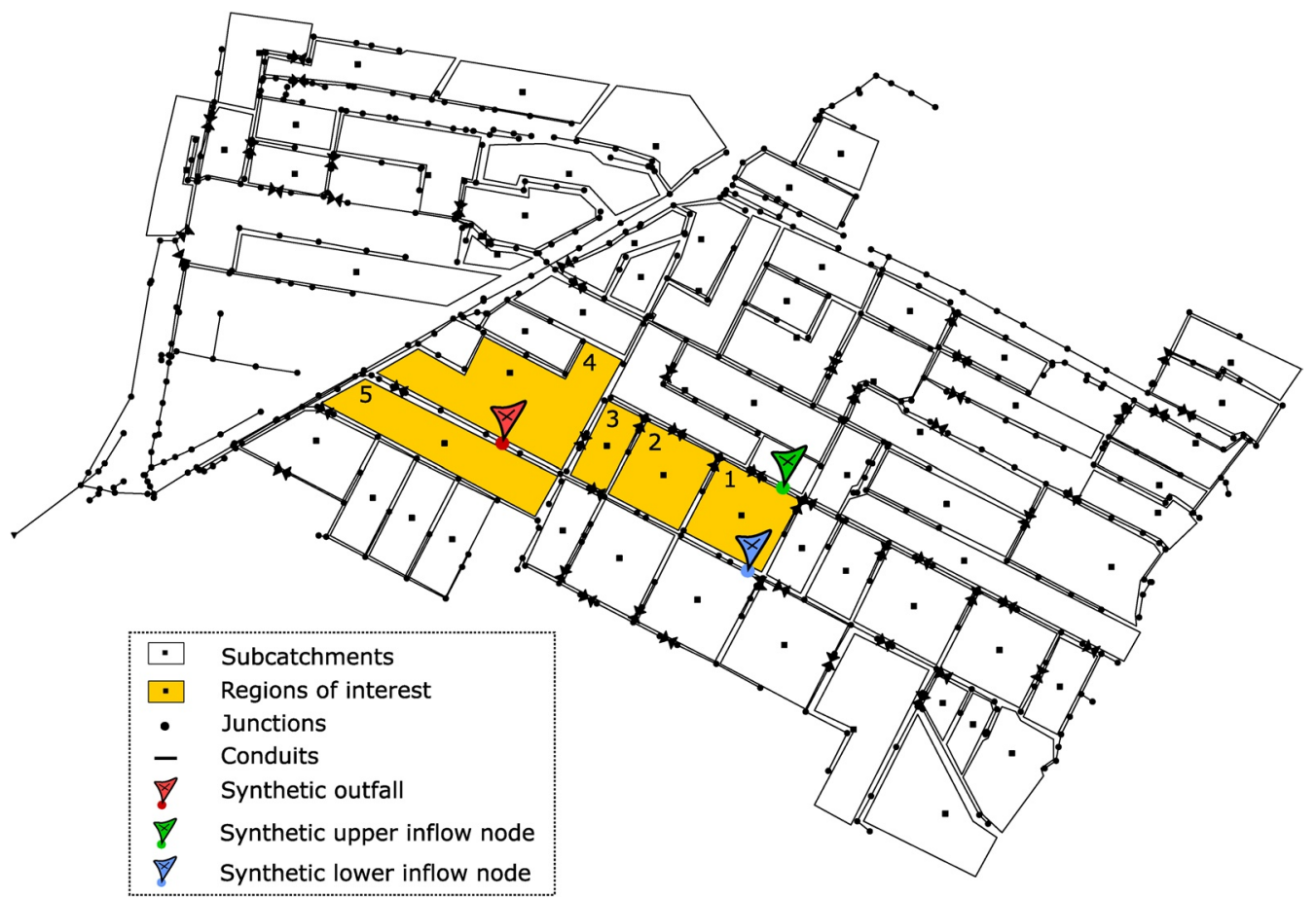

Figure 2. Case study 1 with the region of interest highlighted in yellow. The urban drainage system is artificially divided into two sub-systems, with synthetic manholes representing the cut-nodes between them. The schematic shows the position of the two synthetic inflow nodes (green and blue markers) and the synthetic outfall (red marker) for the region of interest. This case study was taken from the work of Riaño-Briceño et al. (2016).

a subcatchment, spatial distribution, and surface area, were considered for each subcatchment, along with four design objectives in each case study, including minimization of capital cost, flood volume, average flood duration (in both case studies), and TSS (case study 1) or average peak runoff (case study 2). Accordingly, the following four objective functions were considered:

$$
\text { Minimize }: \boldsymbol{F}=\left(F_{\text {Cost }}, F_{\text {Flood } V}, F_{\text {Flood } D}, F_{\mathrm{TSS}} \text { or } F_{\text {Peak } R}\right)
$$

in which $F_{\text {Cost }}$ is overall SuDS capital cost, $F_{\text {Flood } V}$ represents system flood volume, $F_{\text {FloodD }}$ is average flood duration in the catchment, $F_{\text {TSS }}$ denotes the TSS discharge at the outfall (case study 1 ), and $F_{\text {PeakR }}$ is the mean peak runoff (case study 2).

The capital cost was calculated for the SuDS as follows:

$$
F_{\mathrm{Cost}}=\sum_{i=1}^{N_{S}} \sum_{j=1}^{N_{t}}\left(c_{i j} \times a_{i j}\right)
$$

where $N_{s}$ is the number of subcatchments, $N_{t}$ is number of types of SuDS in each subcatchment, $a_{i j}$ is the surface area of each drainage asset, and $c_{i j}$ denotes its capital cost per unit area, which was extracted from online databases (Washington State Department of Ecology \& Herrera Environmental Consultants, 2012) and vendors' catalogs.

The flood volume objective function was defined as:

$$
\boldsymbol{F}_{\text {Flood } V}=\sum_{i=1}^{N_{m}} F V
$$

where $N_{m}$ is the number of manholes and $F V$ is the overall flood volume at each manhole.

The average flood duration in the drainage system was calculated as: 


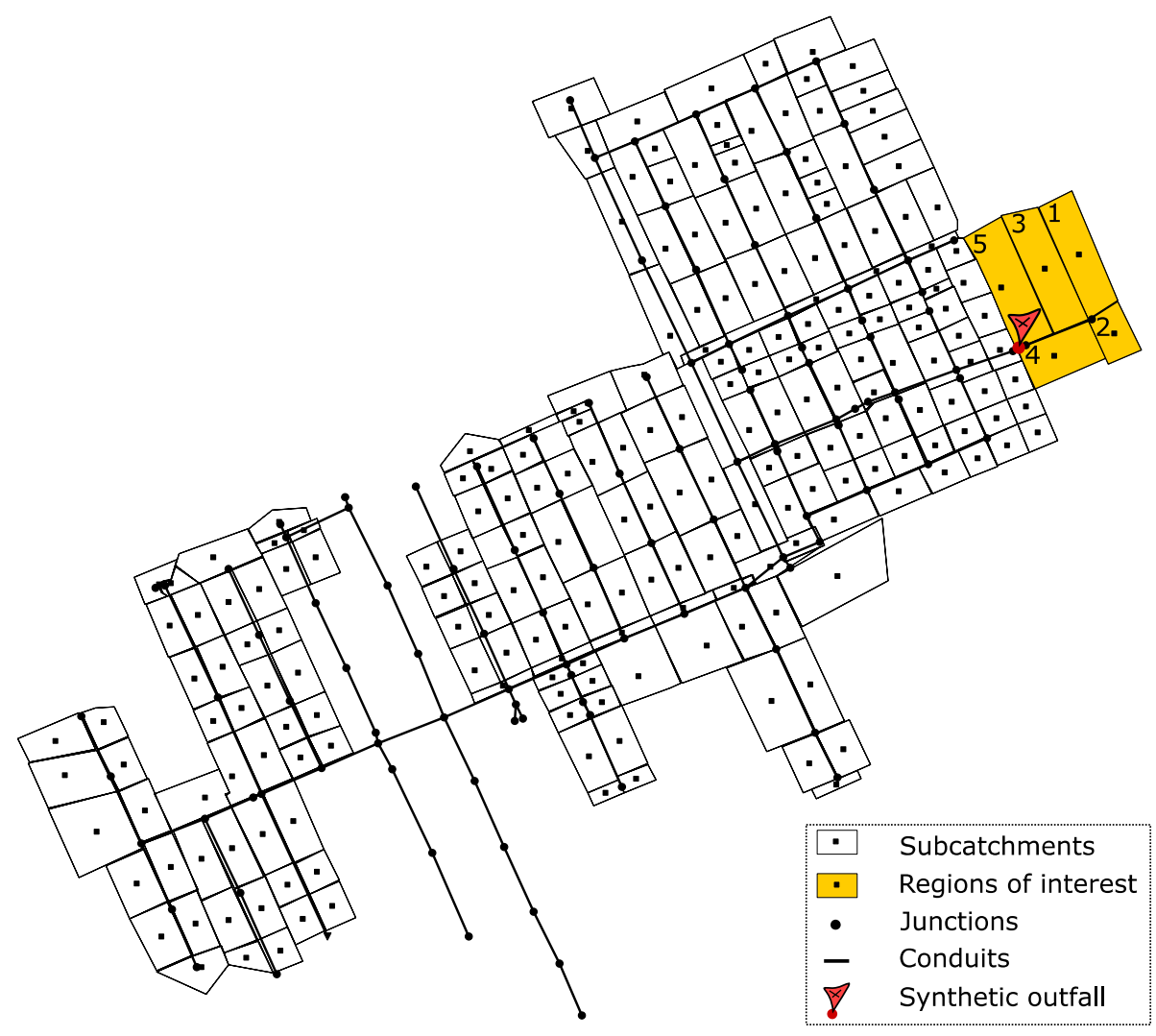

Figure 3. Case study 2 and region of interest highlighted in yellow. The urban drainage system is artificially divided into two sub-systems, with a synthetic outfall (red marker) between them. In this case the region of interest is located in the upstream part of the catchment and has no inflows from upstream. This case study was taken from the work of $\mathrm{K}$. Eckart et al. (2018).

$$
\boldsymbol{F}_{\text {Flood } D}=\frac{\sum_{i=1}^{N_{f}} \boldsymbol{F} \boldsymbol{D}_{i}}{N_{f}}
$$

where $F D$ is flood duration at each manhole and $N_{f}$ denotes the number of flooded manholes. The overall TSS load at the outfall (case study 1) and average peak runoff were (case study 2) obtained from SWMM simulation results.

Two different optimization models were applied in this study. In case study 1, the optimization model uses CNSGA-II for multi-objective optimization, and SWMM to represent the system dynamics in the region of interest, with the boundary condition at the outfall provided by the MLP neural network described in Section 2.2.1. Each optimization individual contains 20 integer values, corresponding to two different types of SuDS and their surface area in each of the 5 subcatchments in the case study area. The integer values defining the SuDS types and their surface areas can vary within the intervals ( 07$)$ and (0 20), respectively.

An infinite number of generations were allowed to be explored by CNSGA-II, and the search process was set to stop when the average relative change in the spread of Pareto solutions was less than the function tolerance of $10^{-4}$ over 50 consecutive iterations. With these settings, the optimization model converged in $1.6 \mathrm{~h}$ after 18,000 function evaluations, as opposed to $34.8 \mathrm{~h}$ required if the entire system had been considered in the numerical simulations. In case study 2, Borg MOEA was applied to the disaggregated region and the search process was set to stop after 30,000 function evaluations. The hypervolume indicator was used to check the convergence of the optimization process, and the results are presented in the Appendix (Figure A1). 


\section{Results and Discussion}

The surrogate model used to represent the hydraulic head at the cut-node must be able to map the decision variables involved in SuDS design to the resulting hydraulic head time-series at the cut-node, which makes the problem highly non-linear. In this study, 2,000 random SuDS configurations were simulated in SWMM to obtain 2,000 sets of hydraulic head time-series, each of them consisting of 20 time steps. The time-series data set was randomly divided into training, validation, and testing sets comprising $70 \%, 15 \%$, and $15 \%$ of the available data, respectively. To compare the efficiency of the ANN used for emulation, the same input-output data were considered in the training process. To find the best MLP architecture, trial and error analyses were conducted, where we changed the number of layers and the number of neurons for each layer, and we evaluated the error in the hydraulic head compared with that predicted by simulating the whole system. In case study 1, out of about 130 different MLP architectures for the outfall emulation model with up to two hidden layers, and up to 20 neurons for each layer, the best performing network has 7 neurons in its first layer, and 15 neurons in its second hidden layer. The same number of MLP architectures was tested for the inflow emulation model, and the best-performing architecture was found to have7 neurons in its first layer and 12 neurons in its second hidden layer. Moreover, the best performing MLP network in case study 2 was obtained with 14 and 15 neurons in its first and second layers, respectively, with a similar trial and error procedure.

In GRNN training, the smoothing factor $\sigma$ was found to be 0.35 and 0.25 for the emulation models of the outfall and inflow nodes in case study 1 , and 0.67 for the emulation model of the outfall node in case study 2 based on a trial and error analysis where 40 different GRNN architectures were tested in each case. The resulting ANN predictions were compared with the numerical outputs in terms of mean square error (MSE), root mean square error (RMSE), mean error $(\mu)$, standard deviation of errors $(\sigma)$, and correlation coefficient $(R)$. These error metrics are defined as follows:

$$
\begin{gathered}
\text { MSE }=\frac{1}{n} \sum_{i=1}^{n}\left(h_{i}-\hat{h}_{i}\right)^{2} \\
\text { RMSE }=\sqrt{\frac{1}{n} \sum_{i=1}^{n}\left(h_{i}-\hat{h}_{i}\right)^{2}} \\
\mu=\frac{1}{n} \sum_{i=1}^{n}\left(h_{i}-\hat{h}_{i}\right)^{2} \\
\sigma=\sqrt{\frac{1}{n} \sum_{i=1}^{n}\left(h_{i}-\hat{h}_{i}\right)^{2}} \\
R=\frac{\operatorname{cov}(h, \hat{h})}{\sqrt{\operatorname{var}(h) \cdot \sqrt{\operatorname{var}(\hat{h})}}}
\end{gathered}
$$

where $n$ is the number of data, $h$ and $\hat{h}$ stand for numerical and predicted hydraulic head, respectively, and $\operatorname{cov}(\cdot)$ and $\operatorname{var}(\cdot)$ denote covariance and variance. Similar error metrics were used for the inflow rates.

The results of the application of MLP and GRNN to the prediction of the hydraulic head and inflows at the synthetic outfall and inflow nodes in the case study area are presented in Table 1. Figure 4 compares the emulated hydraulic heads at the outfall cut-nodes with that predicted by SWMM considering the whole drainage system for both case studies. Here, the red markers represent model results, whereas the continuous lines represent identity $(h=\hat{h})$. The figure shows good agreement between the predictions of the 
Table 1

Comparison of Calculated RMSE, MSE, $R, \sigma$, and $\mu$ of MLP and GRNN Predictions for the Synthetic Outfall and Inflow Nodes

\begin{tabular}{|c|c|c|c|c|c|c|c|}
\hline & & & RMSE & $M S E$ & $R$ & $M$ & $\sigma$ \\
\hline \multirow[t]{6}{*}{ Case study 1} & MLP & Outfall & 0.024274 & 0.000589 & 0.998321 & 0.000291 & 0.024274 \\
\hline & & Upper inflow node & 0.488066 & 0.238209 & 0.999998 & -0.01455 & 0.487890 \\
\hline & & Lower inflow node & 0.160321 & 0.025703 & 0.999998 & -0.00365 & 0.160293 \\
\hline & GRNN & Outfall & 0.038364 & 0.001472 & 0.995886 & -0.00041 & 0.038364 \\
\hline & & Upper inflow node & 0.767876 & 0.589634 & 0.999996 & -0.01542 & 0.767798 \\
\hline & & Lower inflow node & 0.215930 & 0.046626 & 0.999996 & -0.00804 & 0.215802 \\
\hline \multirow[t]{2}{*}{ Case study 2} & MLP & Outfall & 0.028521 & 0.000813 & 0.998867 & -0.00013 & 0.028524 \\
\hline & GRNN & Outfall & 0.131974 & 0.017417 & 0.976418 & 0.00110 & 0.131985 \\
\hline
\end{tabular}

Abbreviations: GRNN, generalized regression neural network; MLP, multilayer perceptron; MSE, mean square error; RMSE, root mean square error

surrogate model and the full drainage model for the outfall cut-node, and that MLP has better predictive performance ( $R=0.998$ for case study $1, R=0.999$ for case study 2$)$ than GRNN ( $R=0.996$ for case study $1, R=0.976$ for case study 2 ).

(a)

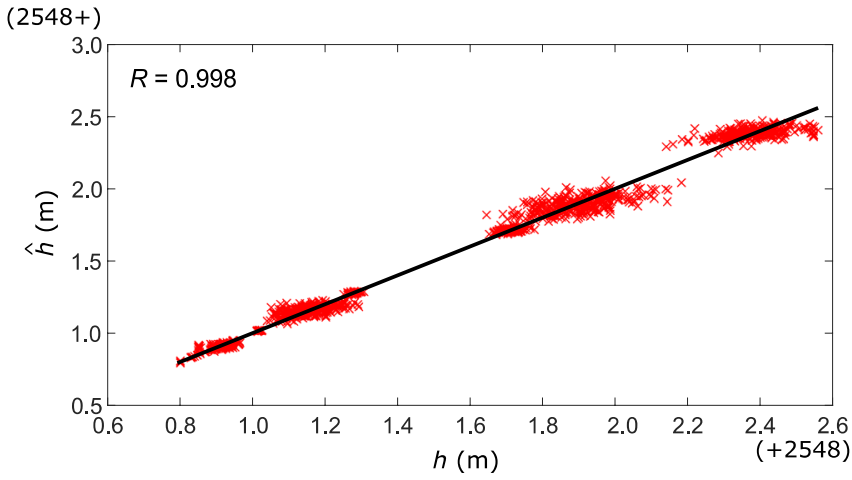

(c)

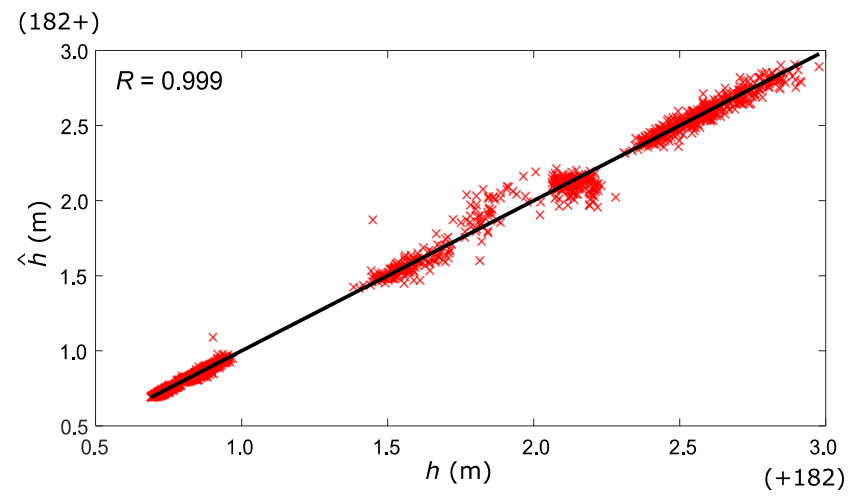

(b)



(d)



Figure 4. Scatter plots of the numerical results and (a) multilayer perceptron (MLP) predictions for case study 1, (b) GRNN predictions for case study 1 , (c) MLP predictions for case study 2, and (d) generalized regression neural network (GRNN) predictions for case study 2 . The plots show that, in both case studies, the MLP network outperforms GRNN in estimating the hydraulic head at the synthetic outfall node of the disaggregated drainage system. Here, $h$ and $h \hat{~ s t a n d}$ for numerical and predicted hydraulic heads, respectively. Hydraulic head values are reported in meters above the reference elevation, $2,548 \mathrm{~m}$ and $182 \mathrm{~m}$ for the first and second case studies, respectively. 
(a)



(c)



(b)



(d)



Figure 5. Error distributions of (a) multilayer perceptron (MLP) predictions for case study 1, and (b) generalized regression neural network (GRNN) predictions for case study 1, (c) MLP predictions for case study 2, and (b) GRNN predictions for case study 2 at the synthetic outfall node. The height of each bar indicates the number of predictions. A smaller standard deviation means better performance on average.

Error distributions of MLP and GRNN predictions at the synthetic outfall node are illustrated in Figure 5, in which the height of each bar indicates the number of predictions with similar errors. In both cases, the mean of the distribution is close to zero with slightly smaller values for MLP, which implies better performance on average.

Figure 6 compares the time-series of hydraulic head at the synthetic outfall predicted by MLP and GRNN with those calculated by the full drainage model for five random SuDS configurations in each case study. Both surrogate models provided a reasonably good estimate of the time-series of hydraulic head, but the MLP model outperformed GRNN by providing more accurate predictions.

In Figure 6, it is evident that changing SuDS design in the region of interest impacts hydraulic head time-series at the synthetic nodes. A 30\% change in the peak hydraulic head values as the surface area of SuDS is changed from $0 \%$ to $20 \%$ of the subcatchment is especially evident in case study 2 . To exemplify the performance of the selected MLP architecture we evaluated flood volume, flood duration, and TSS loads using the disaggregated model with the synthetic boundary conditions and the full model of the entire drainage network for a randomly selected SuDS design in case study 1 . The prediction error was found to be about $3.6 \%$ for flood volume values with accurate predictions of flood durations. The results obtained for flood duration and flood volume at each manhole in the region of interest are summarized in Table 2.

Table 3 compares the computational times for training and executing the MLP network and GRNN with those of the SWMM simulations for the whole urban catchment in both case studies. The computations were performed on a single processor of an Intel Core i7-8565U CPU clocked at $4.60 \mathrm{GHz}$ with $8 \mathrm{~GB}$ of DDR4 RAM.

Table 3 indicates that GRNN benefits from a significantly faster training process, but the time required for training by both MLP and GRNN is smaller compared to the time required to generate the training datasets. GRNN has a larger execution time compared to MLP, and therefore MLP is preferable for optimization 
(a)

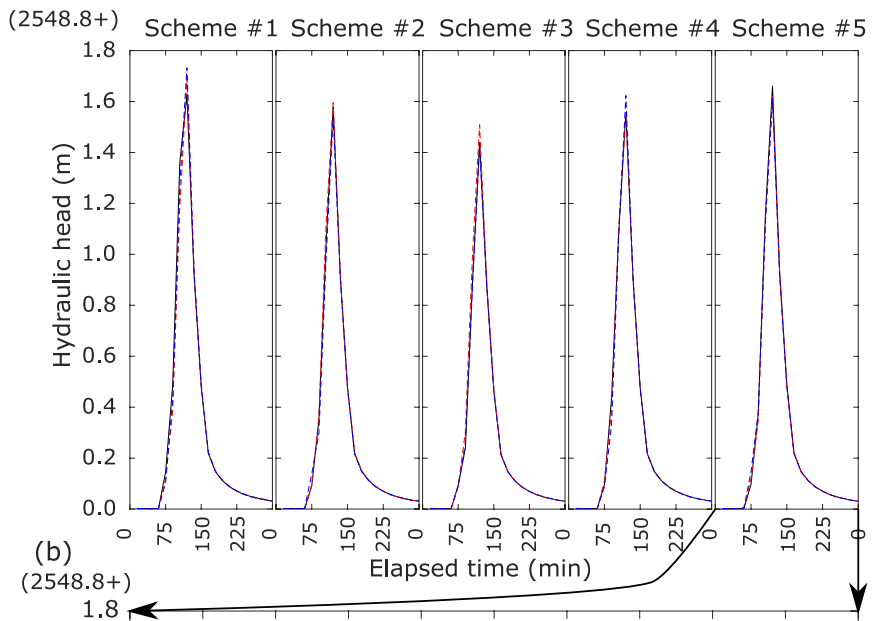

$(2548.8+)$

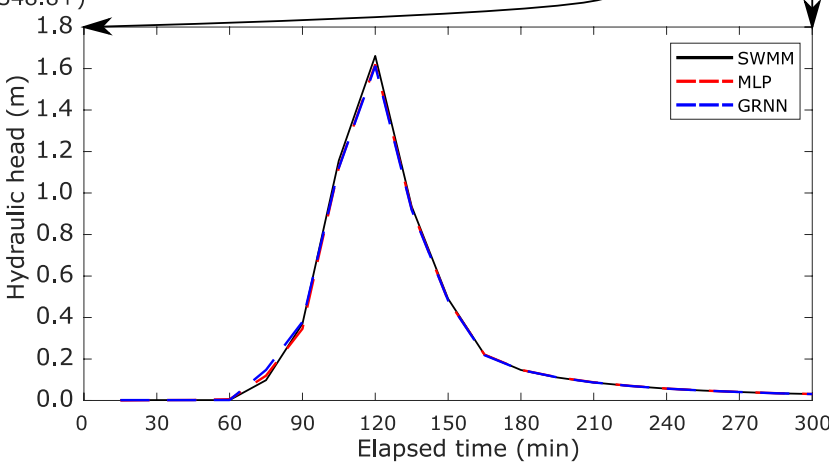

(c)

(182+) Scheme \#1 Scheme \#2 Scheme \#3 Scheme \#4 Scheme \#5
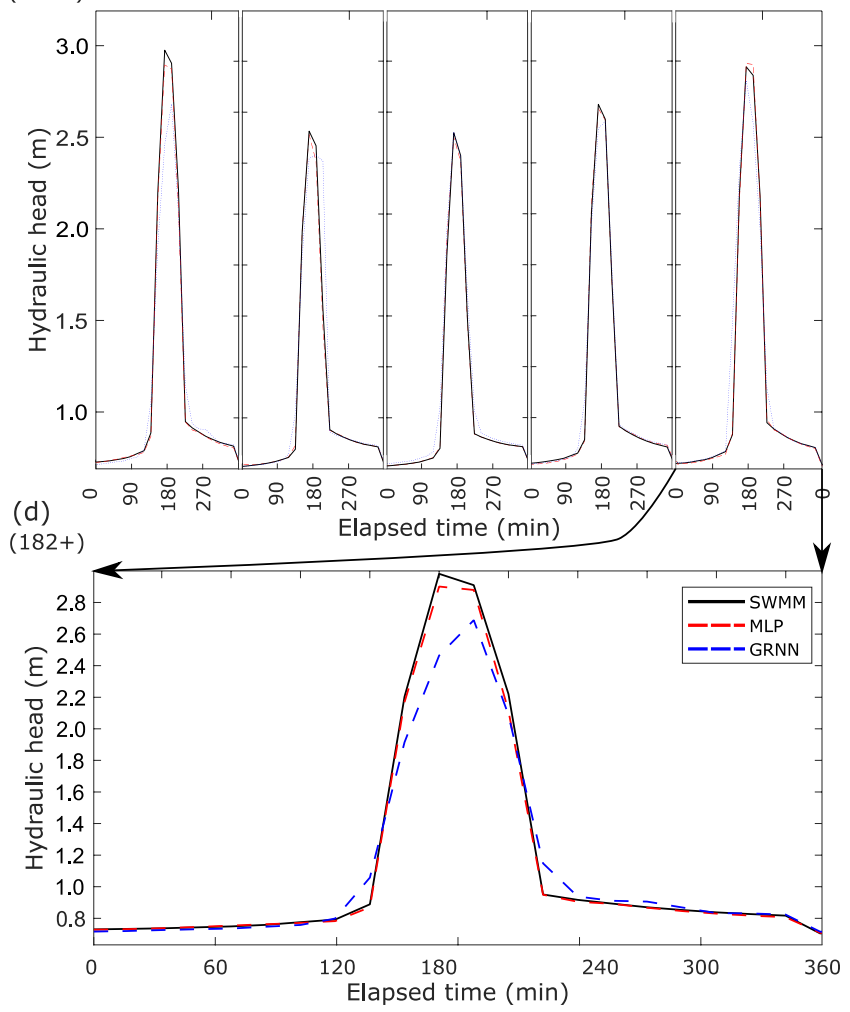



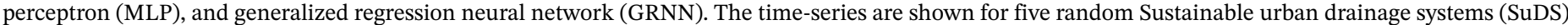
schemes in (a) case study 1 , with (b) results in particular for the 5 th scheme in case study 1 ; and five random SuDS schemes in (c) case study 2 , with (d)

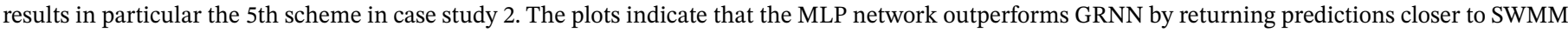
simulations. It can be seen that changing SuDS design in the region of interest impacts the hydraulic head at the synthetic nodes.

problems that require a large number of objective function evaluations. While the computational time required to train the surrogate models was relatively small in the case studies presented in this paper, the training process can become more computationally expensive if the optimization problem involves a larger number of decision variables, or if multiple rainfall events are considered. Yet, if the decision variables are confined to a region of interest, the overall computational cost required for optimization would be significantly higher if the whole drainage network had to be simulated.

Table 2

Comparison of Flood Volume and Flood Duration Results of SWMM Simulations in Flooded Manholes of a Random SuDS Scheme in Case Study 1

\begin{tabular}{lcccccc}
\hline & \multicolumn{2}{c}{ Flood duration (hrs) } & & \multicolumn{2}{c}{ Flood volume $\left(\mathrm{m}^{3}\right)$} \\
\cline { 2 - 3 } \cline { 6 - 7 } Manhole & Reduced map & Global model & & Reduced map & $\begin{array}{c}\text { Global } \\
\text { model }\end{array}$ \\
\hline PMI92736 & 0.25 & 0.25 & & 43 & 48 \\
PMI92751 & 0.37 & 0.37 & & 340 & 344 \\
PMI92782 & 0.34 & 0.34 & & 179 & 178 \\
\hline
\end{tabular}

Abbreviations: SuDS, sustainable urban drainage systems; SWMM, Storm Water Management Model.
Figure 7 illustrates a four-dimensional plot of the Pareto-optimal solutions obtained in both case studies. Capital cost, flood volume, and flood duration are shown on the $x, y, z$-axes, respectively. TSS and average peak runoff rate values are represented by marker sizes in Figures $7 \mathrm{a}$ and $7 \mathrm{~b}$, respectively, where larger markers represent larger TSS loads and/or peak runoff rates. The four-dimensional plots provide an overview of the system performance and design metrics for the solution space.

Figure 8 depicts a parallel axis plot (Inselberg, 2009) of the objective functions together with the final SuDS schematic, as an example, for case study 1 . The parallel axes represent optimization objectives, in which the preferred direction is downwards, and the lines connecting the axes represent Pareto-optimal designs. The ideal solution candidate is a horizontal line at the bottom of the axes. This visualization technique allows practitioners to interactively set final design constraints on the problem objectives. Here, the lower third of each non-monetary objective was 
Table 3

Surrogate Model Training and Execution Time Comparison With Numerical Results in Case Study 1

\begin{tabular}{llc}
\hline & \multicolumn{1}{c}{ Operation } & Execution time (ms) \\
\hline Case study 1 & Numerical simulation of global catchment & 8,199 \\
& Numerical simulation of the reduced model & 163 \\
& Optimization function evaluation for global catchment & 8,585 \\
& Optimization function evaluation for the reduced model & 394 \\
& MLP training & 35,635 \\
& GRNN training & 292 \\
MLP prediction & 9 \\
GRNN prediction & 64 \\
Numerical simulation of global catchment & 3,498 \\
Numerical simulation of the reduced model & 153 \\
Optimization function evaluation for global catchment & 2,982 \\
& Optimization function evaluation for the reduced model & 251 \\
MLP training & GRNN training & 29,899 \\
& MLP prediction & 286 \\
GRNN prediction & 10
\end{tabular}

Abbreviations: GRNN, generalized regression neural network; MLP, multilayer perceptron.

selected as an acceptable range of solutions to narrow down the solution space. A candidate solution with lowest capital cost among those within the specified ranges was then singled out as the final SuDS design for the region of interest. This is illustrated in Figure 8b, where the bar color represents the type of asset,

(a)
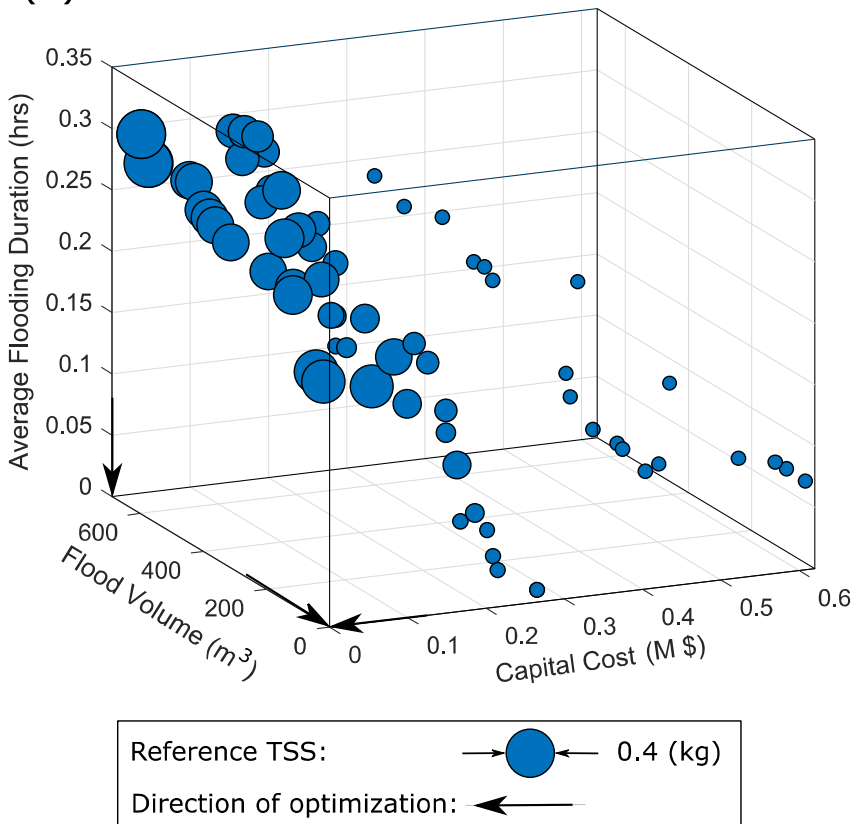

(b)


Figure 7. Four-dimensional representation of trade-offs between design objectives in (a) case study 1 and (b) case study 2, where marker size represents overall total suspended solids (TSS) load and average peak runoff rate in the first and second case studies, respectively. The controlled version of NSGA-II (CNSGA-II) and Borg Multi-Objective Evolutionary Algorithm (MOEA) optimization algorithms were applied to the first and second case studies, respectively. 
(a)

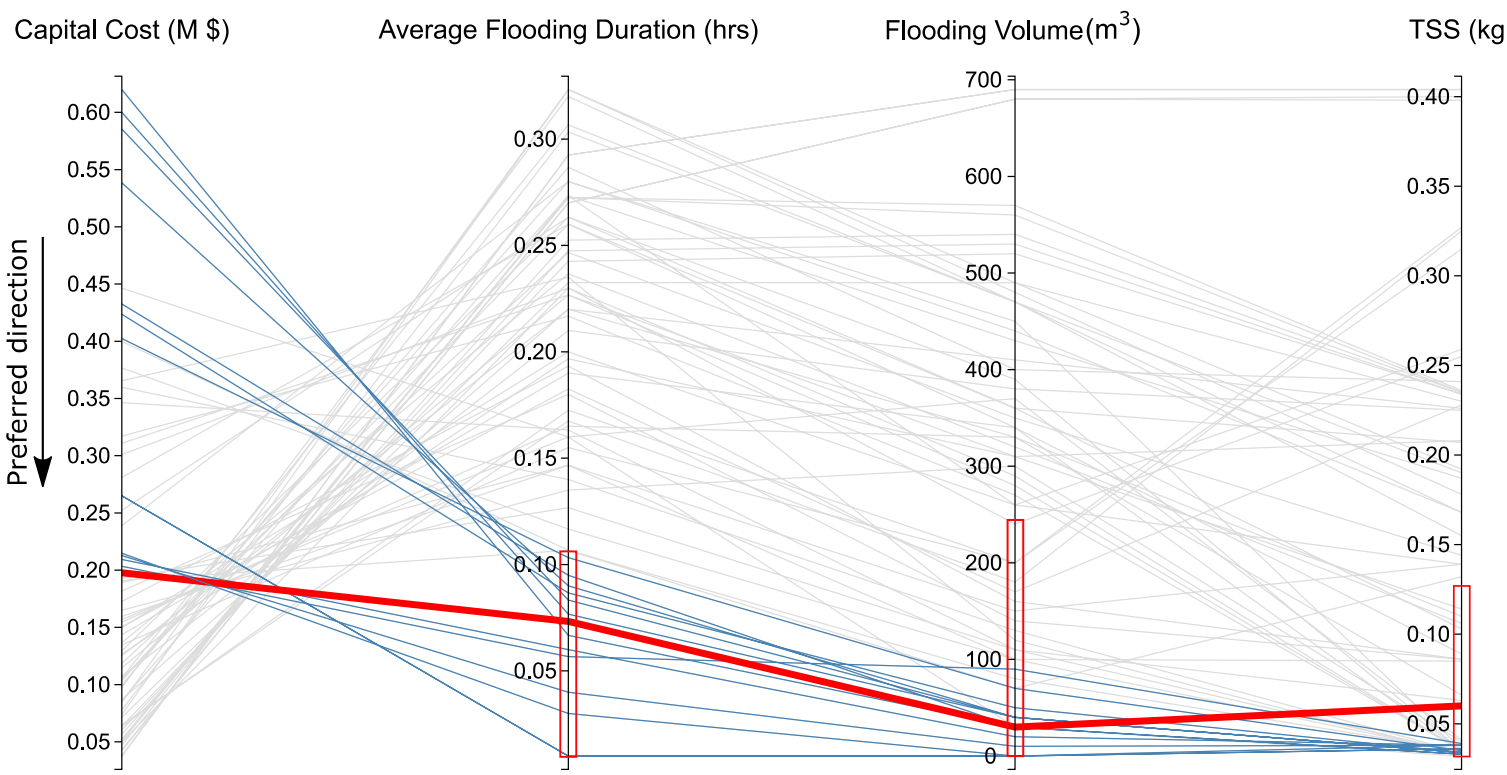

(b)

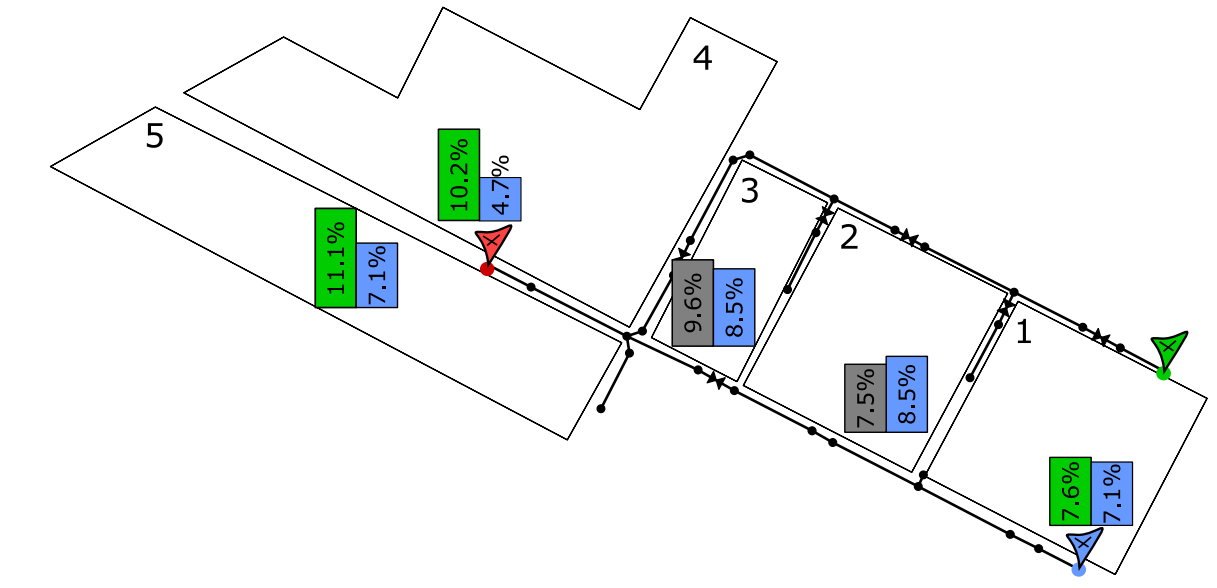

\begin{tabular}{lll}
\hline Subcatchments & $\bigotimes$ Synthetic lower inflow node & $\square$ Bio-retention Cell \\
- Junctions & $\bigotimes$ Synthetic outfall & $\square$ Rain Garden \\
- Conduits & $\bigotimes$ Synthetic upper inflow node $\quad \square$ Permeable pavement
\end{tabular}

Figure 8. Many-objective optimization of Sustainable urban drainage systems (SuDS) in case study 1; (a) parallel axis plot of the non-dominated solutions; (b) Pareto-optimal SuDS types, combination, spatial distribution, and surface areas of the selected portfolio (red line in panel a) described as a percentage of the respective subcatchment area. Each axis represents an objective and each line connecting the axes denotes performance of a candidate solution. The red boxes on the axes of panel (a) are interactive filter bars that allow drainage designers to isolate a subset of Pareto-optimal designs that meet their preferences. The arrow shows the direction of preference.

and the bar height represents the surface area expressed as a percentage of the total surface area of the subcatchment. An identical approach can be applied to single out a final SuDS design portfolio for case study 2.

Figure 8 shows how the proposed disaggregation-emulation approach can help practitioners efficiently use an optimization model for SuDS design in an area of interest without considering the remaining part of drainage system. The spatial distribution on SuDS components in Figure 8b pertains to the portfolio highlighted with a bold red line in Figure 8a. Here, the optimization model explores potential combinations of green, blue, and grey urban drainage infrastructure for each subcatchment to maximize efficiency of the SuDS design in reducing stormwater runoff and pollution according to geographical and hydrological characteristics of each subcatchment (Alves et al., 2019; K. Eckart et al., 2018). Accordingly, SuDS components 
appear as pairs of sustainable drainage assets in each subcatchment. Here the color of each bar stands for a particular SuDS type, whereas the bar height is proportional to the SuDS surface area.

\section{Conclusions}

A new surrogate-based optimization approach was presented for disaggregation and optimization of largescale sustainable urban drainage networks. The approach is applicable to problems where part of a network needs to be optimized, and allows the computational cost of simulating the system dynamics for the whole system to be significantly reduced by disaggregating the region of interest and representing the remaining part of the system using an interface boundary condition. The latter is determined from a surrogate model that maps changes in the optimization variables to hydraulic head and total inflow time-series at synthetic outfalls and inflow nodes, respectively, at the cut-points between the region of interest and the remaining part of the drainage network. Artificial neural networks (ANNs) are used as surrogate models for both the inflow and outflow boundary conditions. The proposed approach was demonstrated with an application to a many-objective optimization problem involving the design of sustainable urban drainage infrastructure for capacity expansion in two urban catchments. The decision variables include the types of sustainable drainage assets, their combinations and surface area in five different subcatchments. Four objective functions are considered in each case study, that is, the minimization of capital cost, flood volume, flood duration, and total suspended solids in case study 1, or average peak runoff rate in case study 2 . For the ANN representing the interface boundary conditions at the cut-points, two alternative approaches were evaluated: a multilayer perceptron (MLP) network and a generalized regression neural network (GRNN). Results show that both emulation models can provide acceptable approximations of the hydraulic head and total inflow at the synthetic outfall and inflow nodes, respectively, but MLP provided more accurate and efficient predictions, making it suitable for use in real-world design problems. GRNN benefits from a faster training process, which makes it efficient for problems with large calibration datasets. Using the proposed disaggregation-emulation approach, the computational time required for a single drainage simulation in the region of interest was about 50 times smaller than that required for simulation of the whole drainage network, allowing to speed-up the optimization process by factors of 22 and 12 in the first and the second case study, respectively.

In this study, the proposed approach was used to expand the capacity of an existing drainage network within a region of interest using sustainable drainage assets. However, the approach can be used more generally for optimization, calibration or trial and error analysis of urban drainage, water distribution, and a broader variety of water resources networks. In a similar way to the application presented in this work, a surrogate model may be used in design and control problems concerning water distribution networks to represent changes in flows and hydraulic heads at the boundary of a region of interest. Future work could use the proposed approach to optimize large water resources networks by partitioning them into a number of subregions and optimizing them sequentially.

\section{Appendix A: Hypervolume}

The hypervolume of a Pareto-front represents the volume of the multi-dimensional space enveloped by the front (Zitzler et al., 2003). The hypervolume indicator was used as the main convergence criterion for Borg MOEA in case study 2 and as a further check for convergence of CNSGA-II in case study 1 . The evolution of the hypervolume during the optimization process is presented in Figure A1a for case study 1 and Alb for case study 2 . 
(a)

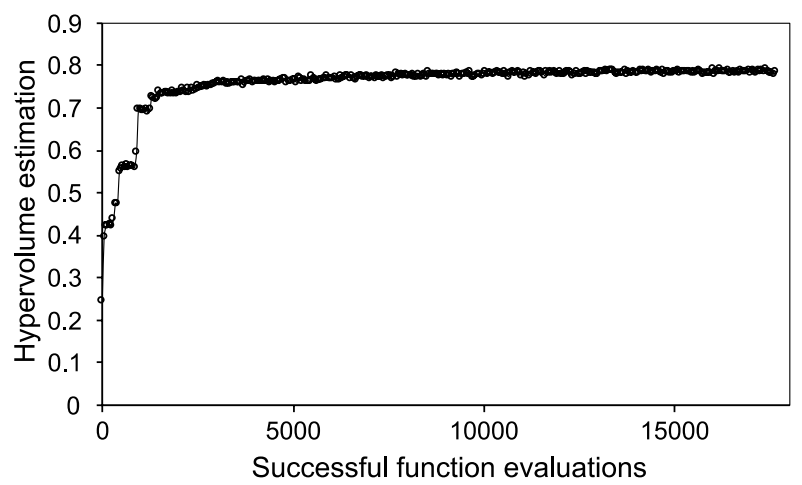

(b)

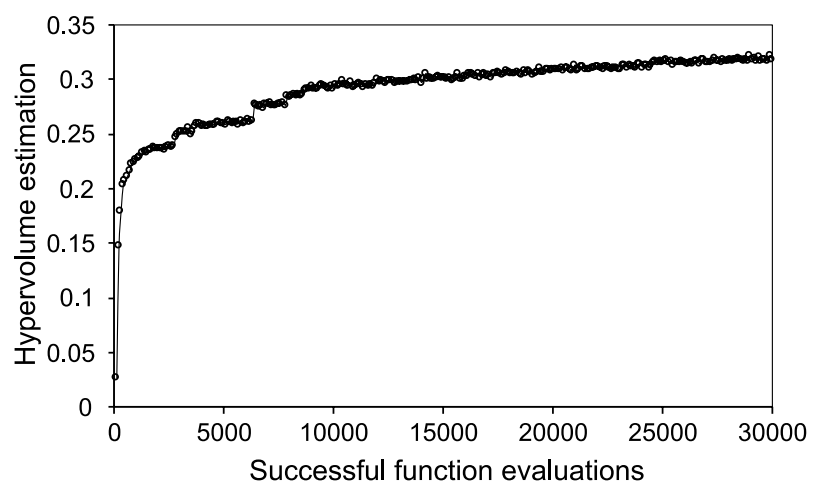

Figure A1. Hypervolume evolution throughout the optimization process for (a) case study 1 and (b) case study 2.

Acknowledgments

This work was jointly supported by Thames Water Utilities Ltd and The University of Manchester. The authors would like to thank Andrew Hagger for valuable discussions and suggestions.

\section{Data Availability Statement}

The original case studies used in this work were taken from Riaño-Briceño et al. (2016) (https://github.com/ water-systems/MatSWMM) and K. B. C. Eckart (2015).

\section{References}

Abou Rjeily, Y., Abbas, O., Sadek, M., Shahrour, I., \& Hage Chehade, F. (2017). Flood forecasting within urban drainage systems using NARX neural network. Water Science and Technology, 76(9), 2401-2412. https://doi.org/10.2166/wst.2017.409

Abou Rjeily, Y., Abbas, O., Sadek, M., Shahrour, I., \& Hage Chehade, F. (2018). Model predictive control for optimising the operation of urban drainage systems. Journal of Hydrology, 566, 558-565. https://doi.org/10.1016/j.jhydrol.2018.09.044

Alves, A., Gersonius, B., Kapelan, Z., Vojinovic, Z., \& Sanchez, A. (2019). Assessing the co-benefits of green-blue-grey infrastructure for sustainable urban flood risk management. Journal of Environmental Management, 239, 244-254. https://doi.org/10.1016/j. jenvman.2019.03.036

Broad, D. R., Dandy, G. C., \& Maier, H. R. (2005). Water distribution system optimization using metamodels. Journal of Water Resources Planning and Management, 131(3), 172-180. https://doi.org/10.1061/(ASCE)0733-949610.1061/(asce)0733-9496(2005)131:3(172)

Chang, F. J., Chen, P. A., Lu, Y. R., Huang, E., \& Chang, K. Y. (2014). Real-time multi-step-ahead water level forecasting by recurrent neural networks for urban flood control. Journal of Hydrology, 517, 836-846. https://doi.org/10.1016/j.jhydrol.2014.06.013

Chiang, Y. M., Chang, L. C., Tsai, M. J., Wang, Y. F., \& Chang, F. J. (2010). Dynamic neural networks for real-time water level predictions of sewerage systems-covering gauged and ungauged sites. Hydrology and Earth System Sciences, 14(7), 1309-1319. https://doi.org/10.5194/ hess-14-1309-2010

Deb, K., \& Goel, T. (2001). Controlled elitist non-dominated sorting genetic algorithms for better convergence. In: Lecture notes in computer science (including subseries lecture notes in artificial intelligence and lecture notes in bioinformatics) (Vol. 1993, pp. 67-81). Berlin: Springer. https://doi.org/10.1007/3-540-44719-9_5

Deb, K., Pratap, A., Agarwal, S., \& Meyarivan, T. (2002). A fast and elitist multiobjective genetic algorithm: NSGA-II. IEEE Transactions on Evolutionary Computation, 6(2), 182-197. https://doi.org/10.1109/4235.996017

Du, K. L., \& Swamy, M. N. S. (2006). Neural networks in a softcomputing framework. Neural Networks in a Softcomputing Framework, 1-566. https://doi.org/10.1007/1-84628-303-5

Duan, H. F., Li, F., \& Yan, H. (2016). Multi-objective optimal design of detention tanks in the urban stormwater drainage system: LID implementation and analysis. Water Resources Management, 30(13), 4635-4648. https://doi.org/10.1007/s11269-016-1444-1

Eckart, K., McPhee, Z., \& Bolisetti, T. (2018). Multiobjective optimization of low impact development stormwater controls. Journal of Hydrology, 562, 564-576. https://doi.org/10.1016/j.jhydrol.2018.04.068

Eckart, K. B. C. (2015). Multiobjective optimization of low impact development stormwater controls under climate change conditions electronic theses and dissertations. University of Windsor.

Fleming, P. J., Purshouse, R. C., \& Lygoe, R. J. (2005). Many-objective optimization: An engineering design perspective. In: Lecture notes in computer science (Vol. 3410, pp. 14-32). https://doi.org/10.1007/978-3-540-31880-4_2

Geng, R., Yin, P., \& Sharpley, A. N. (2019). A coupled model system to optimize the best management practices for nonpoint source pollution control. Journal of Cleaner Production, 220, 581-592. https://doi.org/10.1016/j.jclepro.2019.02.127

Gironás, J., Roesner, L. A., Rossman, L. A., \& Davis, J. (2010). A new applications manual for the storm water management model (SWMM). Environmental Modelling \& Software, 25(6), 813-814. https://doi.org/10.1016/j.envsoft.2009.11.009

Hadka, D., \& Reed, P. (2013). Borg: An auto-adaptive many-objective evolutionary computing framework. Evolutionary Computation, 21(2), 231-259. https://doi.org/10.1162/EVCO_a_00075

Hooshyaripor, F., \& Yazdi, J. (2017). A new methodology for surcharge risk management in urban areas (case study: Gonbad-e-Kavus city). Water Science and Technology, 75(4), 823-832. https://doi.org/10.2166/wst.2016.567

Hornik, K., Stinchcombe, M., \& White, H. (1989). Multilayer feedforward networks are universal approximators. Neural Networks, 2(5), 359-366. https://doi.org/10.1016/0893-6080(89)90020-8 
Inselberg, A. (2009). Parallel coordinates: Visual multidimensional geometry and its applicationsParallel coordinates: Visual multidimensional geometry and its applications. New York: Springer New York. https://doi.org/10.1007/978-0-387-68628-8

James, W., Rossman, L. A., \& James, W. R. C. (2010). Water system models - user's guide to SWMM 5 (13th ed.). CHI.

Kim, H. I., Keum, H. J., \& Han, K. Y. (2019). Real-time urban inundation prediction combining hydraulic and probabilistic methods. Water, 11(2), 1-18. https://doi.org/10.3390/w11020293

Latifi, M., Rakhshandehroo, G., Nikoo, M. R., \& Sadegh, M. (2019). A game theoretical low impact development optimization model for urban storm water management. Journal of Cleaner Production, 241, 118323. https://doi.org/10.1016/j.jclepro.2019.118323

Lin, R., Zheng, F., Savic, D., Zhang, Q., \& Fang, X. (2020). Improving the effectiveness of multiobjective optimization design of urban drainage systems. Water Resources Research, 56(7). https://doi.org/10.1029/2019WR026656

Liu, G., Chen, L., Shen, Z., Xiao, Y., \& Wei, G. (2019). A fast and robust simulation-optimization methodology for stormwater quality management. Journal of Hydrology, 576, 520-527. https://doi.org/10.1016/j.jhydrol.2019.06.073

Macro, K., Matott, L. S., Rabideau, A., Ghodsi, S. H., \& Zhu, Z. (2019). OSTRICH-SWMM: A new multi-objective optimization tool for green infrastructure planning with SWMM. Environmental Modelling \& Software, 113, 42-47. https://doi.org/10.1016/j.envsoft.2018.12.004

Mahmoodian, M., Carbajal, J. P., Bellos, V., Leopold, U., Schutz, G., \& Clemens, F. (2018). A hybrid surrogate modelling strategy for simplification of detailed urban drainage simulators. Water Resources Management, 32(15), 5241-5256. https://doi.org/10.1007/ s11269-018-2157-4

Mahmoodian, M., Torres-Matallana, J. A., Leopold, U., Schutz, G., \& Clemens, F. H. L. R. (2018). A data-driven surrogate modelling approach for acceleration of short-term simulations of a dynamic urban drainage simulator. Water, 10(12), 1849. https://doi.org/10.3390/ w10121849

Maier, H. R., Jain, A., Dandy, G. C., \& Sudheer, K. P. (2010). Methods used for the development of neural networks for the prediction of water resource variables in river systems: Current status and future directions. Environmental Modelling \& Software, 25(8), 891-909. https://doi.org/10.1016/j.envsoft.2010.02.003

Manocha, N., \& Babovic, V. (2018). Real options, multi-objective optimization and the development of dynamically robust adaptive pathways. Environmental Science \& Policy, 90, 11-18. https://doi.org/10.1016/j.envsci.2018.09.012

Maringanti, C., Chaubey, I., \& Popp, J. (2009). Development of a multiobjective optimization tool for the selection and placement of best management practices for nonpoint source pollution control. Water Resources Research, 45(6). https://doi.org/10.1029/2008WR007094

Meza, J. C., \& Oliva, R. A. (2003). An object oriented library to manage the collection of Schittkowski test problems for nonlinear optimization. In: Proceedings of the 2003 Conference on Diversity in Computing TAPIA '03 (Vol. I). https://doi.org/10.1145/948542.948544

Ngamalieu-Nengoue, U. A., Martínez-Solano, F. J., Iglesias-Rey, P. L., \& Mora-Meliá, D. (2019). Multi-objective optimization for urban drainage or sewer networks rehabilitation through pipes substitution and storage tanks installation. Water, 11(5), 935. https://doi. org/10.3390/w11050935

Owen, N. E., \& Liuzzo, L. (2019). Impact of land use on water resources via a Gaussian process emulator with dimension reduction. Journal of Hydroinformatics, 21(3), 411-426. https://doi.org/10.2166/hydro.2019.067

Penn, R., Friedler, E., \& Ostfeld, A. (2013). Multi-objective evolutionary optimization for greywater reuse in municipal sewer systems. Water Research, 47(15), 5911-5920. https://doi.org/10.1016/j.watres.2013.07.012

Raei, E., Reza Alizadeh, M., Reza Nikoo, M., \& Adamowski, J. (2019). Multi-objective decision-making for green infrastructure planning (LID-BMPs) in urban storm water management under uncertainty. Journal of Hydrology, 579, 124091. https://doi.org/10.1016/j jhydrol.2019.124091

Riaño-Briceño, G., Barreiro-Gomez, J., Ramirez-Jaime, A., Quijano, N., \& Ocampo-Martinez, C. (2016). MatSWMM - An open-source toolbox for designing real-time control of urban drainage systems. Environmental Modelling \& Software, 83, 143-154. https://doi. org/10.1016/j.envsoft.2016.05.009

Rossman, L. A., \& Huber, W. C. (2016). Storm water management model reference manual volume 3 - water quality (revised) (EPA/600/R15/162A). (Vol. I, pp. 231). U.S. Environmental Protection Agency.

Sayers, W., Savic, D., \& Kapelan, Z. (2019). Performance of LEMMO with artificial neural networks for water systems optimisation. Urban Water Journal, 16(1), 21-32. https://doi.org/10.1080/1573062X.2019.1611886

Sayers, W., Savić, D., Kapelan, Z., \& Kellagher, R. (2014). Artificial intelligence techniques for flood risk management in urban environments. In: Procedia Engineering (Vol. 70, pp. 1505-1512). Elsevier Ltd. https://doi.org/10.1016/j.proeng.2014.02.165

Seyedashraf, O., Mehrabi, M., \& Akhtari, A. A. A. A. (2018). Novel approach for dam break flow modeling using computational intelligence. Journal of Hydrology, 559, 1028-1038. https://doi.org/10.1016/j.jhydrol.2018.03.001

Seyedashraf, O., Rezaei, A., \& Akhtari, A. A. A. A. (2018). Application of computational intelligence methods for complex two-phase flow pattern recognition. Journal of the Brazilian Society of Mechanical Sciences and Engineering, 40(1). https://doi.org/10.1007/ s40430-017-0956-9

She, L., \& You, X.-Y. (2019). A dynamic flow forecast model for urban drainage using the coupled artificial neural network. Water Resources Management, 33(9), 3143-3153. https://doi.org/10.1007/s11269-019-02294-9

Specht, D. F. (1991). A general regression neural network. IEEE Transactions on Neural Networks, 2(6), 568-576. https://doi. org/10.1109/72.97934

Tadeusiewicz, R. (1995). Neural networks: A comprehensive foundation Control Engineering Practice. (Vol. 3, pp. 746-747). Prentice Hall PTR. https://doi.org/10.1016/0967-0661(95)90080-2

Triki, A. (2017). Water-hammer control in pressurized-pipe flow using a branched polymeric penstock. Journal of Pipeline Systems Engineering and Practice, 8(4), 04017024. https://doi.org/10.1061/(ASCE)PS.1949-1204.0000277

Vojinovic, Z., Sahlu, S., Torres, A. S., Seyoum, S. D., Anvarifar, F., Matungulu, H., et al. (2014). Multi-objective rehabilitation of urban drainage systems under uncertainties. Journal of Hydroinformatics, 16(5), 1044-1061. https://doi.org/10.2166/hydro.2014.223

Washington State Department of EcologyHerrera Environmental Consultants. (2012). PugetSound stormwater BMP cost database. Herrera Environmental Consultants, Inc. Retrieved from https://fortress.wa.gov/ecy/publications/SummaryPages/1303009.html

Xu, T., Jia, H., Wang, Z., Mao, X., \& Xu, C. (2017). SWMM-based methodology for block-scale LID-BMPs planning based on site-scale multi-objective optimization: A case study in Tianjin. Frontiers of Environmental Science \& Engineering, 11(4). https://doi.org/10.1007/ s11783-017-0934-6

Yazdi, J., Mohammadiun, S., Sadiq, R., Salehi Neyshabouri, S. A. A., \& Alavi Gharahbagh, A. (2018). Assessment of different MOEAs for rehabilitation evaluation of urban stormwater drainage systems - Case study: Eastern catchment of Tehran. Journal of Hydro-Environment Research, 21, 76-85. https://doi.org/10.1016/j.jher.2018.08.002

Yazdi, J., \& Salehi Neyshabouri, S. A. A. (2014). Identifying low impact development strategies for flood mitigation using a fuzzy-probabilistic approach. Environmental Modelling \& Software, 60, 31-44. https://doi.org/10.1016/j.envsoft.2014.06.004 
Zhang, Q., Zheng, F., Jia, Y., Savic, D., \& Kapelan, Z. (2021). Real-time foul sewer hydraulic modelling driven by water consumption data from water distribution systems. Water Research, 188, 116544. https://doi.org/10.1016/j.watres.2020.116544

Zhang, W., Li, J., Chen, Y., \& Li, Y. (2019). A surrogate-based optimization design and uncertainty analysis for urban flood mitigation. Water Resources Management, 33(12), 4201-4214. https://doi.org/10.1007/s11269-019-02355-Z

Zhang, X., He, X., Wei, M., Li, F., Hou, P., \& Zhang, C. (2019). Magnetic flocculation treatment of coal mine water and a comparison of water quality prediction algorithms. Mine Water and the Environment, 38(2), 391-401. https://doi.org/10.1007/s10230-019-00590-9

Zitzler, E., Thiele, L., Laumanns, M., Fonseca, C. M., \& Da Fonseca, V. G. (2003). Performance assessment of multiobjective optimizers: An analysis and review. IEEE Transactions on Evolutionary Computation, 7, 117-132. https://doi.org/10.1109/TEVC.2003.810758 